\title{
TS-torquoselectivity from global conformational profile
}

\author{
Veejendra K. Yadav, ${ }^{* \dagger}$ Arpita Yadav ${ }^{\ddagger}$ and Maddali L. N. Rao $^{\dagger}$ \\ ${ }^{\dagger}$ Department of Chemistry, Indian Institute of Technology, Kanpur 208016, India \\ ${ }^{\ddagger}$ Department of Chemistry, UIET, CSJM University, Kanpur 208024, India
}

\begin{abstract}
From global conformational profile and differential activation energies of conrotatory outward and inward ring openings of all the conformers, it is shown that (a) 3-OMe-cyclobutene must open exclusively outward, and (b) conformers exist for 3-CHO-, 3-COMe-, and 3-NO-cyclobutenes that will open outwards as well. All the conformers of 3-OMe-, 3-CHO-, 3-COMe-, and 3-NO-cyclobutenes are, respectively, within $5.6,3.2,4.0$ and $2.6 \mathrm{kcal} / \mathrm{mol}$ and, hence, abundantly available at room temperature for reaction.
\end{abstract}

KEYWORDS: torquoselectivity, global conformational profile, global activation energy profile

Introduction. It is not necessary that only the most stable conformer of a reactant be considered to understand the stereochemical outcome as it is usually done in most computational studies. This is so because chemical reactions are controlled by orbital interactions in the transition state (TS) structures and the best orbital interactions arise from antiperiplanar bonds of complementary nature. ${ }^{1}$ The interaction is Lewis acid-base type, i.e., one bond is electron-rich and the other electron-poor. A molecule can adopt many rapidly equilibrating conformers and the higher lying conformers may react faster than lower lying, including the most stable, conformers for being energetically closer to TS structure due probably to better bond alignments.

For an effective $\sigma \rightarrow \sigma^{*}$ interaction, the two $\sigma$ bonds must be antiperiplanar to each other. Likewise, for $\sigma \rightarrow \pi^{*}$ interaction, the $\sigma$ bond is required to be parallel to the $p$ orbitals of $\pi$ bond. In $n \rightarrow \sigma^{*}$ interaction category, the axis of lone pair orbital $n$ and the $\sigma$ bond need to be antiperiplanar. This notion has been exceptionally well demonstrated by the pioneering work of Berson ${ }^{2}$ who observed, "Reactions predominantly took one of the two symmetryallowed pathways, which though suffered from high steric interactions but benefitted from superior orbital overlap."

3-Substituted cyclobutenes open in conrotatory manner under thermal conditions to form 1,3-dienes with the substituent located on either trans- or cis-double bond depending upon 
its electronic etiquette. ${ }^{3}$ The selectivity of such a ring-opening, termed torquoselectivity, has been predicted by Houk based on the relative activation barriers for outward and inward openings of a stable ground state conformer. ${ }^{4}$ While all the electron-rich and electronreleasing substituents are favored to rotate outwards in excellent agreement with the experiments, such a clear-cut pattern for inward rotation of electron-deficient and electronattracting substituents is absent. For instance, the electron-deficient groups such as acetyl (COMe), carbomethoxy $\left(\mathrm{CO}_{2} \mathrm{Me}\right)$, nitro $\left(\mathrm{NO}_{2}\right)$ and trifluoromethyl $\left(\mathrm{CF}_{3}\right)$ are predicted for outward rotation against the inward rotations of formyl $(\mathrm{CHO})$ and nitroso $(\mathrm{NO})$ groups.

An alternate rationale based on Natural Bond Orbital (NBO) interactions in the TS structure has been advanced. ${ }^{5}$ The NBO interaction approach predicts all electron-rich and electronreleasing substituents to rotate outwards, and electron-deficient and electron-withdrawing substituents inwards. Deviation, if any, from the experimental selectivity was due to reaction equilibration and relative stability of one product over the other. ${ }^{5 i}$

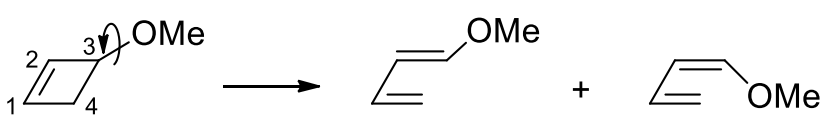

1<smiles>O=C[C@@H]1[CH]CC1</smiles>

2<smiles>CC(=O)C1CCC1</smiles>

3<smiles>O=N[C@H]1[CH]CC1</smiles>

4
$1 \mathrm{a}$<smiles>C=CC=CC=O</smiles>

$2 a$<smiles>C=CC=CC(C)=O</smiles>

$3 a$<smiles>C=CC=CN=O</smiles>

$4 a$
$1 \mathrm{~b}$<smiles>C=CC=CC=O</smiles>

$2 b$<smiles>COC(C)C</smiles>

$3 b$<smiles>[C+]=CC=CNO</smiles>

4b

We chose to study the effect of global conformational changes in the substituent with respect to the cleaving ring bond on torquoselectivity as the same has hitherto not been studied. We chose 3-OMe-cyclobutene 1, 3-CHO-cyclobutene 2, 3-COMe-cyclobutene 3 and 3-NOcyclobutene 4 for the study. 3-OMe-cyclobutene is experimentally known to exclusively open outward. ${ }^{4 b} 3-\mathrm{CHO}-$ cyclobutene opens $>98 \%$ inward and $<2 \%$ outward at $25-70{ }^{\circ} \mathrm{C} .{ }^{4 \mathrm{~d}}$ In 
explicit contrast to 3-CHO-cyclobutene, 3-COMe-cyclobutene opens both ways and furnishes a 3:2 mixture of the outward and inward opened products, respectively, at the reflux temperature of $\mathrm{C}_{6} \mathrm{D}_{6}{ }^{4 e, g}$ The experimental selectivity of 3-NO-cyclobutene has not been reported. However, it has been predicted by Houk to open inward. While OMe is electronrich for the presence of lone pairs of electrons, both $\mathrm{CHO}$ and $\mathrm{COMe}$ are electron-deficient, CHO more than COMe for its better resonance-acceptor strength. ${ }^{6}$ Likewise, NO is also electron-deficient. ${ }^{6}$

Computational Methods. All the geometry optimizations and TS structure searches were carried out using the global hybrid meta-GGA M06-2X density functional and 6-31G(d) basis set at $298 \mathrm{~K}$ and 1.0 atm pressure. ${ }^{7}$ The optimized structures were verified as minima or first order saddle points by harmonic vibrational frequency analysis. The energies reported herein are Gibbs Free Energies [Sum of electronic and thermal Free Energies]. All the calculations were carried out using Gaussian 09 suite of programs. ${ }^{8}$

Results and Discussion. The torsion angles of $\sigma_{\mathrm{O}-\mathrm{Me}}$ in 3-OMe-cyclobutene, $\mathrm{C}=\mathrm{O}$ in 3-CHO- and 3-COMe-cyclobutenes and $\mathrm{N}=\mathrm{O}$ in 3-NO-cyclobutene with $\sigma_{\mathrm{c3}-\mathrm{c} 4}$ bond, as shown in structures 1-4, were altered, $10^{\circ}$ at a time, beginning with a stable ground state conformer of each and the resultant optimized for the geometry. This was followed by locating the TS structures for inward and outward openings of each conformer in each instance. The results for the three substrates are graphically presented in Figure 1.

All the conformers of 3-OMe-, 3-CHO-, 3-COMe- and 3-NO-cyclobutenes are, respectively, within $5.6,3.2$ and $4.0 \mathrm{kcal} / \mathrm{mol}$ and, hence, abundantly available at room temperature. The concentrations of higher lying conformers will rise on raise in temperature. Further, a higher lying conformer may react faster than a low lying conformer for being closer to the TS structure. The cumulative contribution of higher lying conformers to the overall outcome of the reaction, torquoselectivity in the present instance, is therefore likely to be significant.

From absolutely no cross-over of the activation energy profiles and substantial difference between the outward and inward cleavage reactions of 3-OMe-cyclobutene, minimum 12 $\mathrm{kcal} / \mathrm{mol}$, its overwhelming outward cleavage to trans-1-methoxy-1,3-butadiene is guaranteed. This is in excellent agreement with Houk's prediction by considering a lone conformer. 

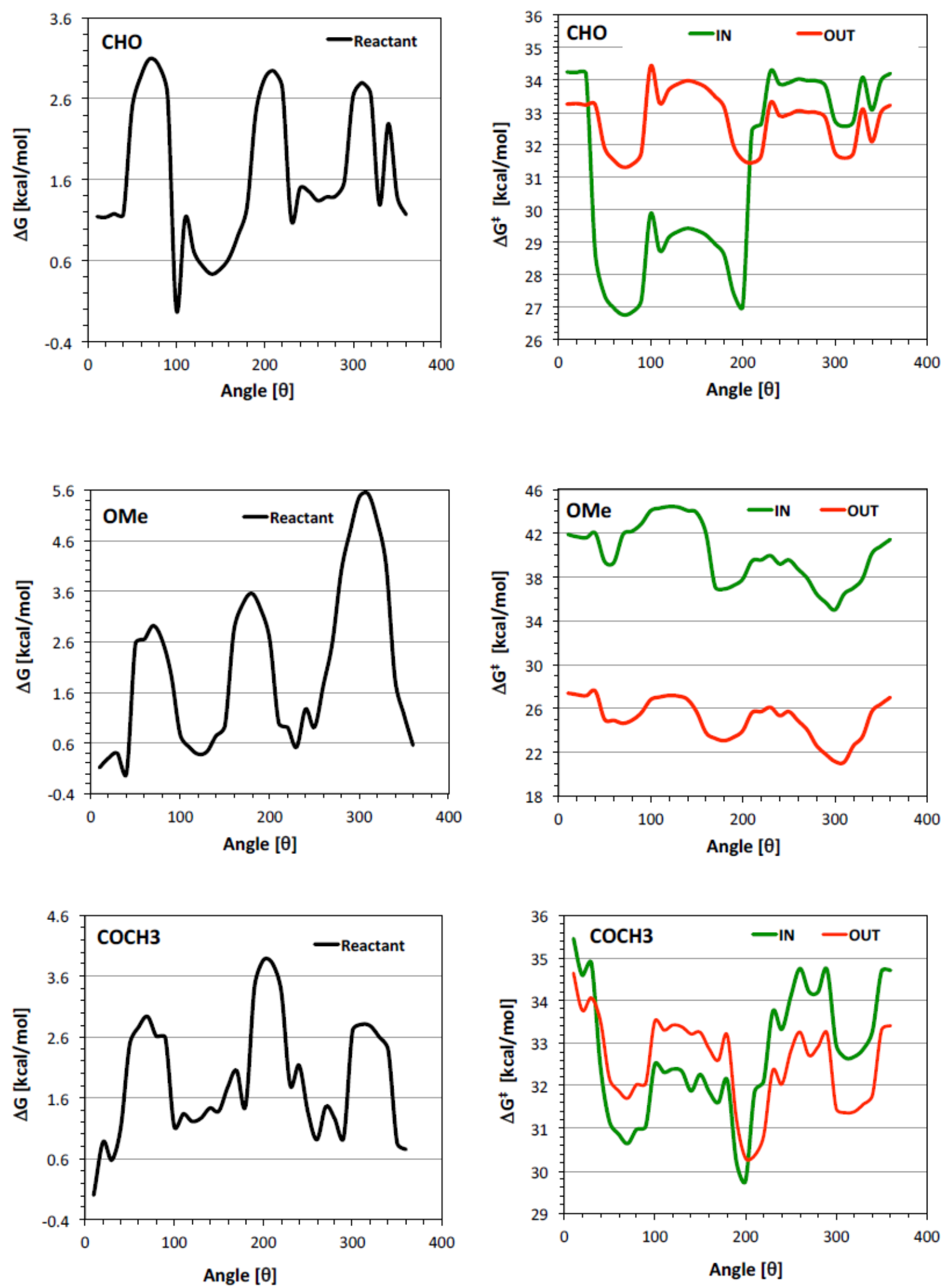

Figure 1. The global conformational surfaces of 3-CHO-, 3-OMe- and 3-COMe-cyclobutenes (left column) and also the inward and outward opening activation energy profiles (right column) at 1 atm and $298 \mathrm{~K}$. 
Except for a tiny region on the far left and reasonably significant region on the right end of activation energy profiles for the reaction of 3-CHO-cyclobutene, the reaction is geared for inward opening for huge margins in the activation energies. The reaction may basically funnel through the conformers in this region, allowing only a small scope to the conformers outside to participate. No wonder, the outward opened product is formed to the extent of $<2 \%$ only. A good cross over and also significant activation energy differences indicate both inward and outward openings of 3-COMe-cyclobutene. Almost half the conformers appear to open inwards and the other half outwards. 3-COMe-cyclobutene furnishes a 3:2 mixture of the outward and inward opened products at $79{ }^{\circ} \mathrm{C}$ in $\mathrm{C}_{6} \mathrm{D}_{6}$. It will be interesting to investigate the conformational profile of 3-COMe-cyclobutene and the corresponding activation energy profiles for ring openings at $79^{\circ} \mathrm{C}$ under the solvent effects of $\mathrm{C}_{6} \mathrm{D}_{6}$ to understand the product distribution.

Houk predicted outward rotation of NO group in the ring opening of 3-NO-cyclobutene. However, from global conformational analysis of the reactant and activation energy profiles given in Figure 2, it is clear that approximately half the conformers are poised for inward rotation. Significantly, all the substrate conformers are within $2.6 \mathrm{kcal} / \mathrm{mol}$ and, hence, abundantly available for reaction at room temperature.
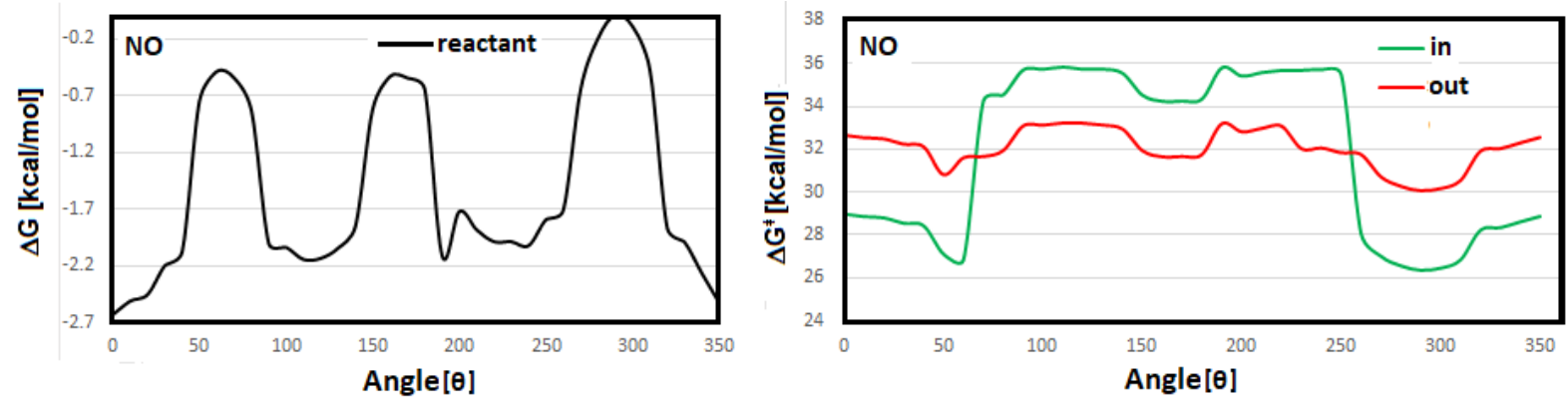

Figure 2. The global conformational surface of 3-NO-cyclobutenes (left column) and the inward and outward opening activation energy profiles (right column) at $1.0 \mathrm{~atm}$ and $298 \mathrm{~K}$

A comparison of ground state conformers profile with corresponding activation energy profiles also shows that higher lying conformers react faster than lower lying conformers for reduced activation barriers. Having taken the most stable ground state conformer alone for investigation, one would predict exclusive inward openings of 3-CHO- and 3-NO- 
cyclobutenes, outward opening of 3-OMe-cyclobutene, and approximately 50:50 opening of 3-COMe-cyclobutene.

Conclusions. The study of global conformational profile and corresponding activation energies predict exclusive outward opening of 3-OMe-cyclobutene, inward opening of 3-CHOcyclobutene with a small scope for outward opening, and competitive outward and inward openings of 3-COMe- and 3-NO-cyclobutenes at $298 \mathrm{~K}$ in the gas phase. The predictions for 3OMe-, 3-CHO- and 3-COMe-cyclobutenes are in line with the experiments. The experimental selectivity of 3-NO-cyclobutene is not reported. 3-Me-3-NO-cyclobutene has been predicted by Houk for inward rotation of the NO group. The outward rotating influence of the Me group, however, also needs to be taken into account. We wish to carry out this study at elevated temperatures to understand its effects on torquoselectivity.

The present approach to the analysis of torquoselectivity is first of the kind. The effect of conformational changes on certain other aspects have lately appeared in the literature..$^{9,10}$

\section{AUTHOR INFORMATION}

\section{Corresponding Author}

*vijendra@iitk.ac.in

\section{Funding Sources}

The authors declare no competing financial interests.

\section{ACKNOWLEDGMENT}

The authors gratefully acknowledge allocation of time on HPC2013 series of supercomputers by the Computer Centre of IIT Kanpur and Dr. DLVK Prasad for processing the data and generating the conformational as well as activation energy profiles.

\section{REFERENCES NAD NOTES}

1. P. Deslongchamps, Stereoelectronic Effects in Organic Chemistry, Pergamon Press, 1983.

2. J. A. Berson, The overlap component of the stereoelectronic factor. Remote control of stereogenicity transfer through the anisotropic influence of a ring. Acc. Chem. Res. 1991, 24, 215-222; and references cited therein 
3. (a) R. B. Woodward, R. Hoffmann, Stereochemistry of Electrocyclic Reaction, J. Am. Chem. Soc. 1965, 87, 395-397. (b) R. B. Woodward, R. Hoffmann, The Conservation of Orbital Symmetry, Angew. Chem. Int. Ed. 1969, $8,781-853$.

4. (a) W. Kirmse, N. G. Rondan, K. N. Houk, Stereoselective substituent effects on conrotatory electrocyclic reactions of cyclobutenes, J. Am. Chem. Soc. 1984, 106, 7989-7991. (b) N. G. Rondan, K. N. Houk, Theory of stereoselection in conrotatory electrocyclic reactions of substituted cyclobutenes, J. Am. Chem. Soc. 1985, 107, 2099-211. (c) K. N. Houk, D. C. Spellmeyer, C. W. Jefford, C. G. Rimbault, Y. Wang, R. D. Miller, Electronic control of the stereoselectivities of electrocyclic reactions of cyclobutenes against incredible steric odds, J. Org. Chem. 1988, 53, 2125-2127. (d) K. Rudolf, D. C. Spellmeyer, K. N. Houk, Prediction and experimental verification of the stereoselective electrocyclization of 3-formylcyclobutene, J. Org. Chem. 1987, 52, 3708-3710. (e) S. Niwayama, E. A. Kallel, D. C. Spellmeyer, C. Sheu, K. N. Houk, Substituent Effects on Rates and Stereoselectivities of Conrotatory Electrocyclic Reactions of Cyclobutenes. A Theoretical Study, J. Org. Chem. 1996, 61, 2813-2825. (f) S. Niwayama, Y. Wang, K. N. Houk, The Torquoselectivity of electrocyclic reactions of 3-donor-3-acceptorsubstituted cyclobutenes, Tetrahedron Lett. 1995, 36, 6201-6204. (g) S. Niwayama, K. N. Houk, Lewis acid reversal of the torquoselectivity of the electrocyclic ring opening of 3-acetlcyclobutene, Tetrahedron Lett. 1993, $34,1251-1254$.

5. (a) M. Murakami, T. Miyamoto, Y. Ito, A Silyl Substituent Can Dictate a Concerted Electrocyclic Pathway: Inward Torquoselectivity in the Ring Opening of 3-Silyl-1-cyclobutene, Angew. Chem., Int. Ed. 2001, 40, 189-190. (b) P. S. Lee, X. Zhang, K. N. Houk, Origins of Inward Torquoselectivity by Silyl Groups and Other $\sigma$-Acceptors in Electrocyclic Reactions of Cyclobutenes, J. Am. Chem. Soc. 2003, 125, 5072-5079. (d) K. Aikawa, Y. Hioki, N. Shimizu, K. Mikami, Catalytic Asymmetric Synthesis of Stable Oxetenes via Lewis Acid-Promoted [2 + 2] Cycloaddition, J. Am. Chem. Soc. 2011, 133, 20092-20095. (e) K. Aikawa, N. Shimizu, K. Honda, Y. Hioki, K. Mikami, Effect of the trifluoromethyl group on torquoselectivity in the $4 \pi$ ring-opening reaction of oxetenes: stereoselective synthesis of tetrasubstituted olefins, Chem. Sci. 2014, 5, 410-415. (f) K. Honda, S. A. Lopez, K. N. Houk, K. Mikami, Mono-, Di-, and Trifluoroalkyl Substituent Effects on the Torquoselectivities of Cyclobutene and Oxetene Electrocyclic Ring Openings, J. Org. Chem. 2015, 80, 11768-11772. The publication concludes, "The torquoselectivities are thus controlled by a competition of $\sigma_{\mathrm{c}-\mathrm{o}} \rightarrow \sigma_{\mathrm{c}-\mathrm{F}} *$ effect and unfavorable closed-shell repulsions. Our calculations suggest that 2-difluoromethyloxetenes prefer inward rotation because the favorable $\sigma_{c-o} \rightarrow \sigma_{c-F} *$ orbital effect outweighs closed-shell repulsions in the transition state." (g) L. Akilandeswari, C. Prathipa, J. Chem. Sci. 2015, 127, 1505-1511. (h) A. Saal, L. Merzoud, NBO analysis of the torquoselectivity of the electrocyclic reactions of mono-substituted cyclobutenes J. Comput. Methods Sci. Eng. 2016, 16, 437-447. (i) A. Yadav, D. L. V. K. Prasad, V. K. Yadav, An NBO-TS predictive approach for torquoselectivity of ring opening in 3-substituted cyclobutenes (2017): Preprint. https://doi.org/10.26434/chemrxiv.5743305.v1.

6. (a) V. K. Yadav, A. Yadav, On the Relative Resonance-Acceptor Abilities of CN, NO, COMe, $\mathrm{CHO}$ and $\mathrm{NO}_{2} \mathrm{Groups}$ (2019): ChemRxiv. Preprint. https://doi.org/10.26434/chemrxiv.8081945.v1. (b) V. K. Yadav, A. Yadav, Activation Energy and NBO Interaction Approaches to the Determination of Relative Resonance Acceptor Strengths of CN, 
$\mathrm{NO}$, COMe, $\mathrm{CHO}$ and $\mathrm{NO}_{2}$ Groups from the Ring-Opening of 1,2-Benzo-3-Carbomethoxycyclobutenes. (2019): ChemRxiv. Preprint. https://doi.org/10.26434/chemrxiv.8239157.v1.

7. Y. Zhao, D. G. Truhlar, The M06 suite of density functionals for main group thermochemistry, thermochemical kinetics, noncovalent interactions, excited states, and transition elements: two new functionals and systematic testing of four M06-class functionals and 12 other functionals, Theor. Chem. Acc. 2008, 120, 215-241.

8. M. J. Frisch, G. W. Trucks, H. B. Schlegel, G. E. Scuseria, M. A. Robb, J. R. Cheeseman, G. Scalmani, V. Barone, B. Mennucci, G. A. Petersson, H. Nakatsuji, M. Caricato, X. Li, H. P. Hratchian, A. F. Izmaylov, J. Bloino, G. Zheng, J. L. Sonnenberg, M. Hada, M. Ehara, K. Toyota, R. Fukuda, J. Hasegawa, M. Ishida, T. Nakajima, Y. Honda, O. Kitao, H. Nakai, T. Vreven, J. A. Montgomery Jr., J. E. Peralta, F. Ogliaro, M. Bearpark, J. J. Heyd, E. Brothers, K. N. Kudin, V. N. Staroverov, T. Keith, R. Kobayashi, J. Normand, K. Raghavachari, A. Rendell, J. C. Burant, S. S. Iyengar, J. Tomasi, M. Cossi, N. Rega, J. M. Millam, M. Klene, J. E. Knox, J. B. Cross, V. Bakken, C. Adamo, J. Jaramillo, R. Gomperts, R. E. Stratmann, O. Yazyev, A. J. Austin, R. Cammi, C. Pomelli, J. W. Ochterski, R. L. Martin, K. Morokuma, V. G. Zakrzewski, G. A. Voth, P. Salvador, J. J. Dannenberg, S. Dapprich, A. D. Daniels, O. Farkas, J. B. Foresman, J. V. Ortiz, J. Cioslowski, D. J. Fox, Gaussian 09, revision C.01, Gaussian, Inc., Wallingford, CT 2009. 9. J. I. Seeman, Effect of conformational change on reactivity in organic chemistry. Evaluations, applications, and extensions of Curtin-Hammett Winstein-Holness kinetics, Chem. Rev. 1983, 83, 83-134.

10. R. V. Lopez, O. N. Faza, C. S. Lopez, Conformational control allows for [3,3]-sigmatropic rearrangements to proceed with torquoselectivity. RSC Adv. 2016, 6, 59181-59184. 


\section{For Table of Contents}

Global conformational profile and differential activation energies of conrotatory ring openings of all the conformers, it is shown that 3-OMe-cyclobutene must open exclusively outward and conformers exist for 3-CHO-, 3-COMe- and 3-NO-cyclobutenes that will open outwards as well. All the conformers in each instance are within a small energy range to be abundantly available at room temperature for reaction.
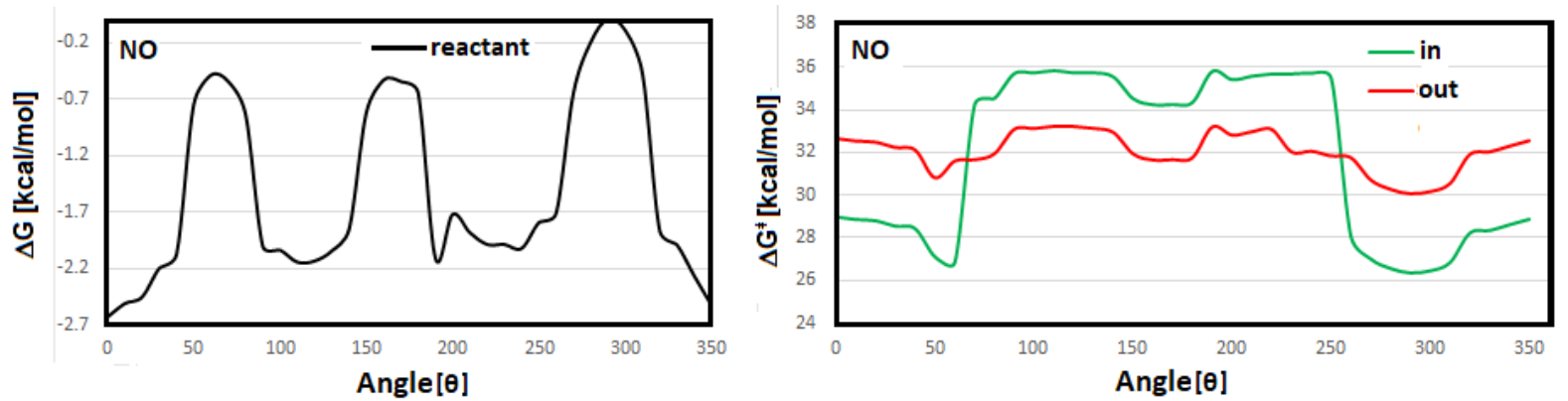